\section{Coronavirus, una historia en desarrollo}

\author{
RICARDO CASTRO L. ${ }^{1}$
}

\section{Coronavirus, a story in progress}

'Editor asociado

Revista Médica de Chile.

Santiago, Chile.

Departamento de Medicina

Intensiva. Pontificia Universidad

Católica de Chile. Santiago, Chile.

Correspondencia a:

Bernarda Morín 488. Providencia.

Santiago, Chile.

rcastro.med@gmail.com
$\mathrm{N}$ os encontramos en medio de una crisis de grandes proporciones. Aproximadamente cada 100 años el mundo experimenta un desafío sanitario de gran envergadura, que exige hasta el extremo las estructuras sanitarias, productivas y sociales en todo el mundo. Sin embargo, el nivel de desarrollo tecnológico y de las ciencias biomédicas que se ha alcanzado al siglo 21 impone nuevos desafíos que, bien conducidos, pueden permitirnos tener un enfrentamiento más exitoso de esta pandemia que el logrado en otras situaciones de la historia humana.

La enfermedad por COVID-19 o novel coronavirus, es una pandemia global de enfermedad respiratoria aguda causada por este virus, que filogenéticamente está estrechamente relacionado con SARS-CoV. Comenzó en diciembre de 2019 en Wuhan, provincia de Hubei en China y fue declarada pandemia global el 11 de marzo de 2020. La mayoría de los casos de COVID-19 ocurren en adultos. Al día de hoy, hay 531.684 casos confirmados en el mundo, con una letalidad de 24.054 casos, lo que equivale a un $4.5 \%$. Esta se tiende a concentrar en adultos mayores. Las definiciones de caso están en permanente revisión. Existen tests disponibles cuya sensibilidad es variable, y se está trabajando aceleradamente en una vacuna en varios centros del mundo, incluyendo en Chile.

Aún se desconocen muchos detalles relacionados con la infección por COVID-19. Lo que está claro es que se trata de un virus enormemente contagioso. Entre las personas con alto riesgo de contraer la infección por COVID-19, se incluyen las que tienen contacto cercano con una persona sintomática que tiene infección confirmada por laboratorio, y que no usa las precauciones recomendadas ni guarda el distanciamiento. COVID-19 se transmite de persona a persona vía gotas de origen respiratorio que produce una persona infectada cuando tose o estornuda. También es posible el contacto con fomites pero se piensa que no es una ruta primaria de transmisión. Se ha visto que las personas infectadas son más contagiosas cuando están más sintomáticas, si bien alguna diseminación puede ser posible antes de presentar síntomas. Datos de Wuhan, muestran que COVID-19 tiene un periodo medio de incubación de 5.2 días y que cada caso transmite la infección a un promedio de otras 2,2 personas.

Los síntomas más comunes incluyen fiebre y tos. La dificultad respiratoria es más característica de neumonía. En cuanto a características de laboratorio, se describe que la linfopenia puede ser común en pacientes con neumonía por COVID-19. Con relación a los estudios de imágenes la radiografía de tórax suele ser anodina pudiendo variar entre normal a mostrar signos de relleno alveolar, derrame pleural, etc. La tomografía axial computada (TAC) suele mostrar opacidades en vidrio esmerilado bilaterales, de predominio periférico. Sin embargo, las imágenes de la TAC varían según la fase de evolución de la neumonía por COVID-19.

En pacientes con sospecha de infección por COVID-19 el manejo inicial depende de la severidad de la enfermedad. Este comienza con oxígeno suplementario, uso restrictivo de fluidos y administración de antimicrobianos empíricos por una eventual coinfección bacteriana. Se desaconseja la administración de corticoides. Los pacientes sintomáticos respiratorios deben ser aislados y estrechamente monitoreados debido a la posibilidad de progresión rápida y fulminante de la falla respiratoria, que suele acompañarse de signos y síntomas de sepsis. Se describe también en pacientes jóvenes cuadros de disfunción cardiaca 
severa que son de rápida evolución y generalmente fatales.

La ventilación mecánica en estos pacientes, según reporte de especialistas que han manejado ya numerosos de casos en China, Italia y España, y otros países, dan cuenta de un requerimiento de oxígeno importante por la hipoxemia, PEEP moderado a alto y una respuesta generalmente muy favorable a las maniobras de reclutamiento. En caso de deterioro respiratorio, la ventilación en posición prono debe instaurarse precozmente, en ciclos largos de 48 a $72 \mathrm{~h}$. Son pacientes que van a permanecer en ventilación mecánica por 15 días al menos, lo que está imponiendo una sobrecarga enorme en los sistemas de salud por varias razones: el manejo ventilatorio de estos pacientes es logísticamente complejo, dada la extrema rigurosidad que hay que cumplir con las precauciones de contacto y aislamiento respiratorio, el cuidado que debe tenerse con procedimientos que generen aerosol, partiendo desde la intubación orotraqueal hasta maniobras de aspiración, etc., y los desafíos que representa manejar pacientes pronados.

Otro aspecto fundamental asociado con la sobrecarga de los sistemas sanitarios tiene que ver con asuntos del personal sanitario. La tensión permanente de estar en riesgo de contraer la infección por COVID-19 durante el manejo de los pacientes críticos, la misma incomodidad que genera portar los elementos de protección personal por varias horas, y muchas veces la imposibilidad de estar en contacto con familiares fuera del hospital, ha comenzado a generar un aumento del burnout, stress y trastornos emocionales. En cuanto a licencias médicas, estas serán necesarias en aproximadamente el $20 \%$ de la fuerza de trabajo.

Estamos presenciando cambios y redefiniciones con respecto a la comunicación del equipo médico con las familias de los pacientes internados por COVID-19. Si bien la comunicación con la familia debe ser una prioridad desde el principio de la hospitalización, restricciones ineludibles por causa de esta enfermedad están obligando a reformular las estrategias de comunicación con seres queridos de un paciente que se encuentra grave en la UCI, todo un desafío a considerar de ahora en adelante. De cualquier manera, debe buscarse precozmente definiciones claras con la familia respecto de una eventual intubación e ingreso a la unidad de cuidados intensivos (UCI) en caso de deterioro respiratorio, o bien un manejo en una unidad de menor complejidad o incluso un traslado domiciliario con intención de proporcionar cuidado y alivio sintomático. Debemos recordar registrar tales decisiones. Además, elementos bioéticos han convergido en el manejo de estos pacientes debido al número finito de camas críticas que hay en cada país, por lo cual al no existir la posibilidad de ventilar el paciente con seguridad, sistema se han visto superados al no poder proveer de cuidados intensivos a quienes lo necesitan. Esto ha concentrado la mortalidad de los casos en los pacientes fuera de la unidad de cuidado intensivo y a sobreimpuesto otra carga emocional en el personal de salud.

El desafío está lejos de terminar. A medida que se escribe la historia de COVID-19, el personal que labora en las UCI, unidades de intermedio, los servicios de apoyo y relacionados, continuarán entregando lo mejor de sí para manejar estos pacientes, al mismo tiempo de procurar algún espacio de autocuidado y contención mutua. Las familias y los cercanos también escriben su propia historia en medio de este desafío global. Esperemos que el final de la historia de esfuerzo, cansancio y dedicación, se entregue un desenlace favorable a niveles locales y estructurales, permitiendo que emerjan servicios de salud fortalecidos, con mayor aprecio por parte de la comunidad, $y$ con una mayor conciencia de su rol vital en la vida nacional por parte de la autoridad política. 